\title{
Cutaneous Melanoma Clinical Regional Lymph Nodes TNM Finding v7
}

National Cancer Institute

\section{Source}

National Cancer Institute. Cutaneous Melanoma Clinical Regional Lymph Nodes TNM

Finding v7. NCl Thesaurus. Code C88399.

A clinical finding about one or more characteristics of cutaneous melanoma, following the rules of the TNM classification system as they pertain to staging of regional lymph nodes. The TNM clinical and pathologic regional lymph nodes classifications of cutaneous melanoma are not the same. TNM clinical regional lymph nodes findings are based on clinical/radiog raphic exam of the regional lymph nodes. (from AJCC 7th Ed.) 